\title{
Pembedahan Tumor Cerebellopontine Angle: Tehnik Proteksi Otak, Pengawasan Sistem Kardiorespirasi dan Efek Manipulasi Posisi True Lateral
}

\author{
Buyung Hartiyo Laksono \\ Departemen Anestesiologi dan Terapi Intensif Fakultas Kedokteran Universitas Brawijaya - RSUD. Dr Saiful \\ Anwar Malang
}

\begin{abstract}
Abstrak
Tumor cerebellopontine angle (CPA) merupakan jenis neoplasma terbanyak yang ditemukan di fossa posterior. Wanita 32 tahun dengan diagnosa CPA tumor dilakukan pembedahan trepanasi reseksi. Posisi pembedahan true lateral. Tehnik anestesi proteksi otak menggunakan kombinasi total intra vena (TIVA) dan inhalasi. Dilakukan pemasangan pengawasan invasif untuk memantau perubahan sistem kardiorespirasi selama pembedahan. Dilakukan pencegahan dan pemantauan terhadap akibat dari posisi pembedahan. Hasil dari pembedahan didapatkan pengurangan skala nyeri dan peningkatan fungsi neurologis. Tindakan pembedahan pada tumor di daerah CPA merupakan tindakan pembedahan yang sulit dan dapat menimbulkan komplikasi yang fatal. Pengelolaan anestesi untuk tindakan bedah fossa posterior memerlukan pertimbangan yang matang dan sudah ditentukan sebelum dilakukan anestesi. Persiapan pada pasien dengan lesi fossa posterior adalah evaluasi prabedah, premedikasi, induksi, posisi durante, pengelolaan anestesi dan monitoring. Manipulasi selama pembedahan pada batang otak dan saraf kranialis akan menimbulkan akibat pada sistem kardiorespirasi dan dapat fatal. Posisi true lateral mempunyai resiko tersendiri terhadap pasien selama dan pascapembedahan, hal tersebut harus menjadi perhatian khusus oleh ahli anestesi. Anestesi mempunyai peranan yang sangat penting dalam manajemen secara keseluruhan pada pasien ini untuk memberikan manajemen proteksi otak yang maksimal selama pembedahan sehingga memperoleh hasil akhir pembedahan yang sukses.
\end{abstract}

Kata kunci: cerebellopontine angle; fossa posterior; posisi true lateral; proteksi otak

JNI 2019; 8 (3): 190-201

\section{Cerebellopontine Angle Tumor Surgery: Brain Protection Techniques, Cardiorespiratory System Monitoring and True Lateral Position Manipulation Effects}

\begin{abstract}
Cerebellopontine angle (CPA) tumors are the most common neoplasm found in the posterior fossa. A 32-yearold woman diagnosed with CPA tumor underwent resection. The surgery position is true lateral. Brain protection anesthetic techniques use total intravenous (TIVA)-inhalation combination. Invasive monitoring is performed to monitor the cardiorespiratory system during surgery. Prevention and monitoring are done to manage the effect of surgical position. There is a reduction in pain scale and increased neurological function after the surgery. CPA tumor surgery is a difficult procedure and potentially cause fatal complications. The anesthesia management for posterior fossa surgery must be determined before anesthesia. The surgery preparation for posterior fossa lesionspatients consists of surgery evaluation, premedication, induction, durante position, anesthesia management, and monitoring. The brainstem and cranial nerve surgery cause a fatal complication in the cardiorespiratory system. The true lateral position impact the patients' condition during and after surgery. Anesthesia is important to provide maximum brain protection and successful surgery.
\end{abstract}

Key words: cerebellopontine angle; brain protection; fossa posterior; true lateral position

JNI 2019; 8 (3): 190-201 


\section{Pendahuluan}

Tumor pada susunan saraf pusat dijumpai hampir $10 \%$ dari tumor di seluruh tubuh, dengan frekuensi $80 \%$ intrakranial dan $20 \%$ medula spinalis. Di Amerika didapati 35.000 kasus baru dari tumor otak setiap tahun. Angka kejadian tahunan tumor otak primer adalah 7-19,1 dan tingkat mortalitas adalah sebesar 6 per 100.000 penduduk. Insiden tumor otak pada anak-anak terbanyak dekade 1 , sedang pada dewasa pada usia 30-70 dengan puncak usia 40-65 tahun. ${ }^{1}$ Tumor otak atau tumor intrakranial ialah tumor yang timbul di dalam tengkorak atau adanya proses desak ruang. Lokasi tumor terbanyak berada di lobus parietalis $(18,2 \%)$, lainnya tersebar di beberapa lobus otak, suprasellar, medullaspinalis, cerebellum, brainstem, cerebellopontine angle dan multiple. ${ }^{2}$ Tumor cerebellopontine angle (CPA) merupakan jenis neoplasma terbanyak yang ditemukan di fossa posterior, merupakan $5-10 \%$ dari seluruh angka kejadian tumor intracranial. ${ }^{3,4}$

Pengelolaan anestesi untuk tindakan bedah fossa posterior memerlukan pertimbangan yang matang dan sudah ditentukan sebelum dilakukan anestesi. Seperti bagaimana mempertahankan tekanan perfusi otak, respon kardiovaskuler terhadap manipulasi pembedahan dan pencegahan terhadap adanya emboli udara. Yang termasuk fossa posterior antara lain pembedahan untuk tumor CPA, tumor cerebellum, dan tumor batang otak (glioma). Pada anak duapertiga dari tumor otak adalah tumor fossa posterior, sedangkan pada dewasa sebagian tumor fossa posterior berupa neurinoma akuistik, tumor metastase, meningioma dan hemangioblastoma. ${ }^{4,5}$ Usaha terapi untuk menghilangkan gejala dan mencegah komplikasi dapat dilakukan secara konservatif, observatif atau dengan pembedahan tergantung dari gejala klinis yang ditimbulkan. ${ }^{5}$ Posisi pada pembedahan CPA tumor pada umumnya dilakukan dengan posisi true lateral. Akibat dari posisi tersebut mempengaruhi hemodinamik, pernapasan, fungsi syaraf perifer, dan muskuloskeletal. Hal inilah yang akan menjadi perhatian khusus durante operasi. ${ }^{6}$

Tindakan pembedahan pada tumor di daerah CPA merupakan tindakan pembedahan yang sulit dan dapat menimbulkan komplikasi yang fatal. CPA merupakan suatu area yang sempit terisi dengan struktur vaskuler dan jaringan saraf. Pengobatan terhadap tumor ini tergantung dari beratnya keluhan dan besarnya tumor. Laporan terakhir dikatakan $90 \%$ post pembedahan mendekati nilai normal dan $40 \%$ memperbaiki pendengaran. ${ }^{5,6}$ Sehingga dalam makalah ini akan dibahas tentang tumor CPA pada pasien perempuan berusia 32 tahun dengan harapan didapatkan pengetahuan mengenai tumor CPA baik secara teori maupun praktik serta permasalahan yang muncul dalam penatalaksaan kasus ini khususnya pada tatalaksana anestesi pada tumor CPA.

\section{Kasus}

Riwayat Penyakit:

Pasien wanita usia 32 tahun, berat badan 59 $\mathrm{kg}$ datang dengan keluhan sakit kepala sejak 2 tahun yang lalu, hilang timbul, dan semakin lama semakin sering. Enam bulan yang lalu lemah pada tubuh sebelah kiri, pendengaran turun sebelah kanan. Dalam satu bulan ini pasen tidak bisa mendengar sama sekali, dan pandangan mulai kabur. Pasien juga mengeluh kesulitan dalam berjalan, selain kaki dirasakan agak melemah juga pusing sewaktu berjalan. Riwayat penyakit lain disangkal. Riwayat penyakit yang sama di keluarga tidak ada.

\section{Pemeriksaan Fisik}

Pemeriksaan fisik saat prabedah, keadaan umum pasien tampak sakit sedang. Tekanan darah 130/80 mmHg, nadi 95-97 x/menit, frekuensi nafas 14-16 x/menit, tidak tampak sesak, saturasi pulseoxymetri $\left(\mathrm{SpO}_{2}\right)$ 97\%. Kesadaran GCS 456 pupil bulat isokor $3 \mathrm{~mm} / 3 \mathrm{~mm}, \mathrm{RC}+/+$. Gangguan nervus kranialis didapatkan pada N VII dan VIII. Tuli sensorial dextra (D) sangat berat. Otot wajah didapatkan hemiparesis D. Tidak terdapat gangguan fonasi dan menelan. Pemeriksaan sensoris normal, motorik normal pada kedua estremitas. Mata tidak tampak anemis, ptosis ataupun ikterik, visus 4/5,5 - 4/5,5. Mallampati 2, Pemeriksaan paru didapatkan gerakan dada simetris, auskultasi suara nafas vesikuler kanan dan kiri, wheezing (-), ronkhi (-). Pemeriksaan 
jantung diidapatkan bunyi jantung S1 - S2 tunggal, murmur/gallop (-). Abdomen supel, tidak ada nyeri tekan, bising usus kesan normal. Ekstremitas tidak dijumpai edema maupun sianosis tetapi didapatkan hemiparesis D. Elektrokardiogram menunjukkan irama sinus 80x/ menit. Foto thorak AP (Gambar 1) paru-paru dalam batas normal. Hasil CT Scan Kepala (Gambar 2) didapatkan gambaran massa solid heterogen di cerebellopontine angle (CPA) kanan, kemungkinan schwanoma akustik yang menyebabkan moderate obstructive hydrocephalus setinggi ventrikel IV dan herniasi transtentorial upward.

\section{Manajemen Anestesi}

Pasien didiagnosa status fisik ASA 3 tumor CPA dengan gangguan pendengaran, hemiparesis dextra, paresis N.VII dextra, peningkatan tekanan intrakranial (TIK). Pasien direncanakan untuk dilakukan tindakan kraniotomi diseksi tumor. Persiapan preoperatif pasien dilakukan informed consent, dipuasakan makanan padat 8 jam sebelum pembedahan, minuman jernih (clear fluid) 2 jam sebelum pembedahan, persiapan

\section{Pemeriksaan Penunjang}

Pemeriksaan penunjang dan tambahan didapatkan data berikut:

\begin{tabular}{llll}
\hline Pemeriksaan & Hasil & Pemeriksaan & Hasil \\
\hline Hemoglobin & $14 \mathrm{~g} / \mathrm{dl}$ & PT & 9 detik \\
Hematokrit & $39,9 \%$ & APTT & $29,6 \mathrm{detik}$ \\
Leukosit & $11,140 / \mathrm{mm} 3$ & Albumin & $4,68 \mathrm{u} / \mathrm{L}$ \\
Trombosit & $190,000 / / \mathrm{mm} 3$ & GDS & $114 \mathrm{u} / \mathrm{L}$ \\
Natrium & $138 \mathrm{mEq} / \mathrm{L}$ & & \\
Kalium & $3,86 \mathrm{mEq} / \mathrm{L}$ & & \\
Clorida & $106 \mathrm{mEq} / \mathrm{L}$ & & \\
Ureum & $13,8 \mathrm{mg} / \mathrm{dl}$ & & \\
Creatinine & $0,6 \mathrm{mg} / \mathrm{dl}$ & & \\
SGOT & $24 \mathrm{u} / \mathrm{L}$ & & \\
SGPT & $34 \mathrm{u} / \mathrm{L}$ & & \\
\hline
\end{tabular}

ruang perawatan intensif untuk pascapembedahan dan premedikasi dengan pemberian ondansetron $8 \mathrm{mg}$, midazolam $2,5 \mathrm{mg}$ dan ranitidine $50 \mathrm{mg}$ sebelum pembedahan.

\section{Pengelolaan Anestesi}

Pasien dilakukan induksi dengan prinsip proteksi otak melalui kombinasi pemberian fentanyl 100 mcg iv, lidokain $80 \mathrm{mg}$ iv, propofol $100 \mathrm{mg}$ iv. Sebelumnya dilakukan preoksigenasi 5 menit $100 \% \mathrm{O}_{2}$, pemasangan monitor NIBP mode stat, $\mathrm{EKG} 3$ leads, $\mathrm{SpO}_{2}$. Intubasi difasilitasi menggunakan rocuronium $50 \mathrm{mg}$ dengan menggunakan endotracheal tube (ETT) nonkinking no. 7. Hemodinamik terukur tekanan darah 125/60 $\mathrm{mmHg}$, nadi $75 \mathrm{x} / \mathrm{menit}$, frekuensi nafas 20x/menit, saturasi $\mathrm{O}_{2} 99 \%$. Dilakukan pemasangan central venous catheher (CVC) ukuran 7 Franc pada vena subclavia kanan dan arterial line pada arteri radialis kanan. Tekanan darah invasif dan CVP langsung disambung ke monitor secara kontinyu. Dipasang kateter urine dengan resturine 200cc dankateter sondelambung. Cek hemodinamik stabil kemudian pasien diposisikan miring (true lateral) kiri. Anestesi pemeliharaan diberikan isoflurane dengan aliran oksigen dan $\mathrm{N}_{2} 0$ (3:1) kombinasi syringe kontinyu propofol (4-12 cc/jam), ditambahkan suplemen fentanyl $50 \mathrm{mcg} / \mathrm{jam}$, vecuronium 2 $\mathrm{mg} / \mathrm{jam}$, dengan mode ventilasi kontrol volume tidal (VT) $440 \mathrm{cc}$, frekuensi $12 x /$ menit. Saturasi terbaca $99-100 \%$. Mannitol diberikan dengan dosis $1 \mathrm{~g} / \mathrm{kgbb}$ dan kortikosteroid diberikan sesuai program ruangan. Pada posisi miring diberikan pading pada ketiak, dan beberapa titik tumpu lainnya. Posisi kepala difiksasi dengan bantal 


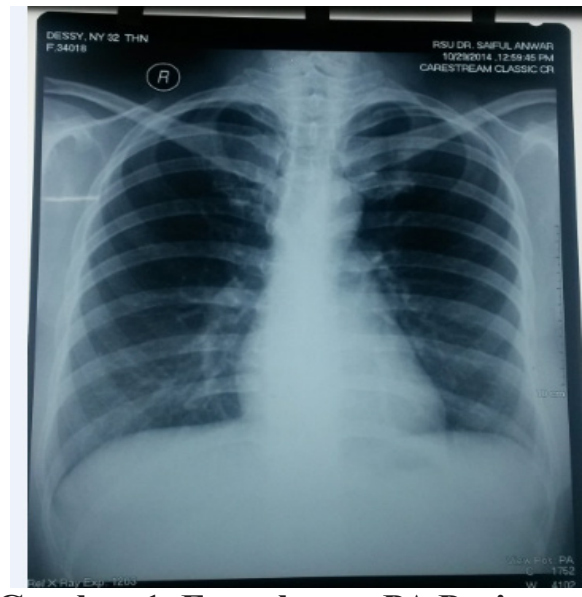

Gambar 1. Foto thorax PA Pasien
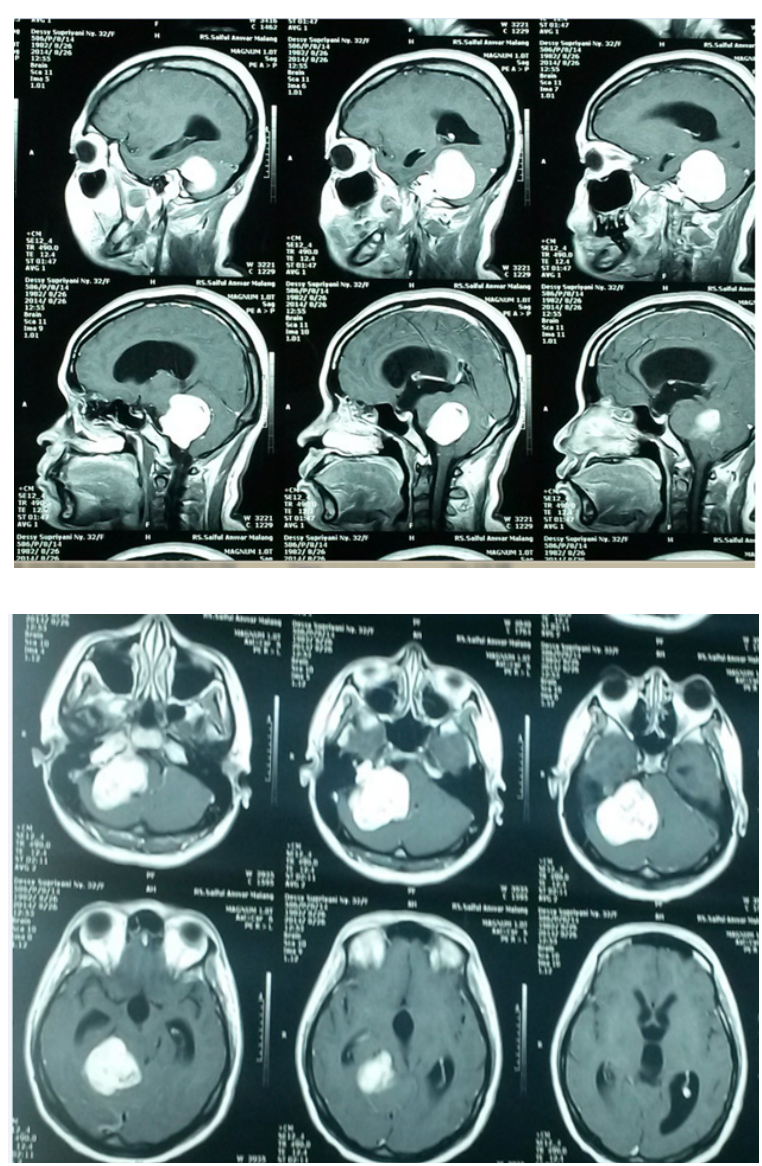

Gambar 2. CT-scan Pasien

donut yang sesuai. Pada sela kaki kanan dan kiri diberi bantal. Dipastikan tidak terjadi bendungan vena jugularis, perfusi perifer ekstremitas dan pengembangan pernafasan baik.

Pembedahan berlangsung selama 7 jam 20 menit. Dilakukan trepanasi dan reseksi tumor
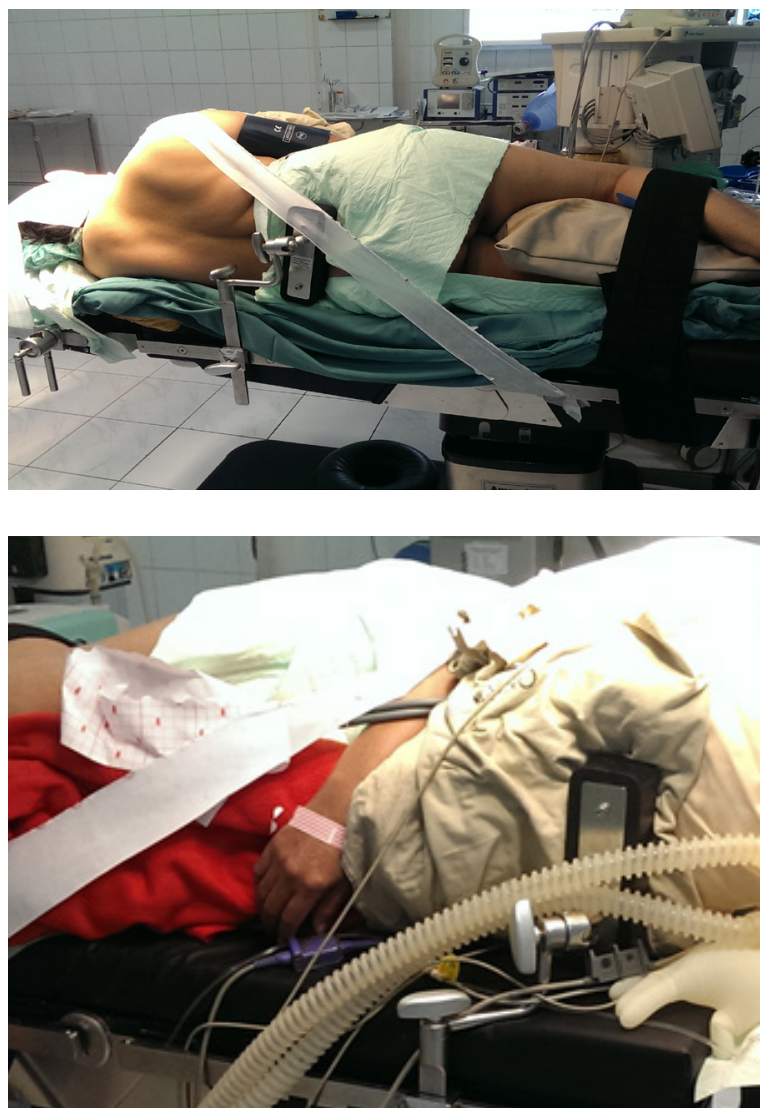

Gambar 3. Posisi pasien miring (true lateral)

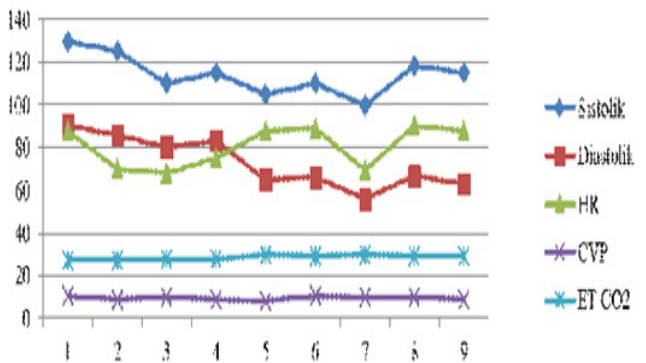

Grafik 1. Hemodinamik selama pembedahan (Keterangan: Sistolik/Diastolik dalam mmHg, HR dalam x/menit, CVP dalam mmHg, ET $\mathrm{CO}_{2}$ dalam $\mathrm{mmHg}$

sekitar $80 \%$. Selama pembedahan hemodinamik relatif stabil meskipun ada beberapa fase terjadi aritmia atau perubahan tekanan darah dan kondisi otak tidak buldging. Fluktuasi hemodinamik ketika dilakukan manipulasi pada saraf dan batang otak. Jika terjadi perubahan akan dikomunikasikan dengan operator dan persiapan obat antiaritmia dan vasopressor sudah dilakukan. 

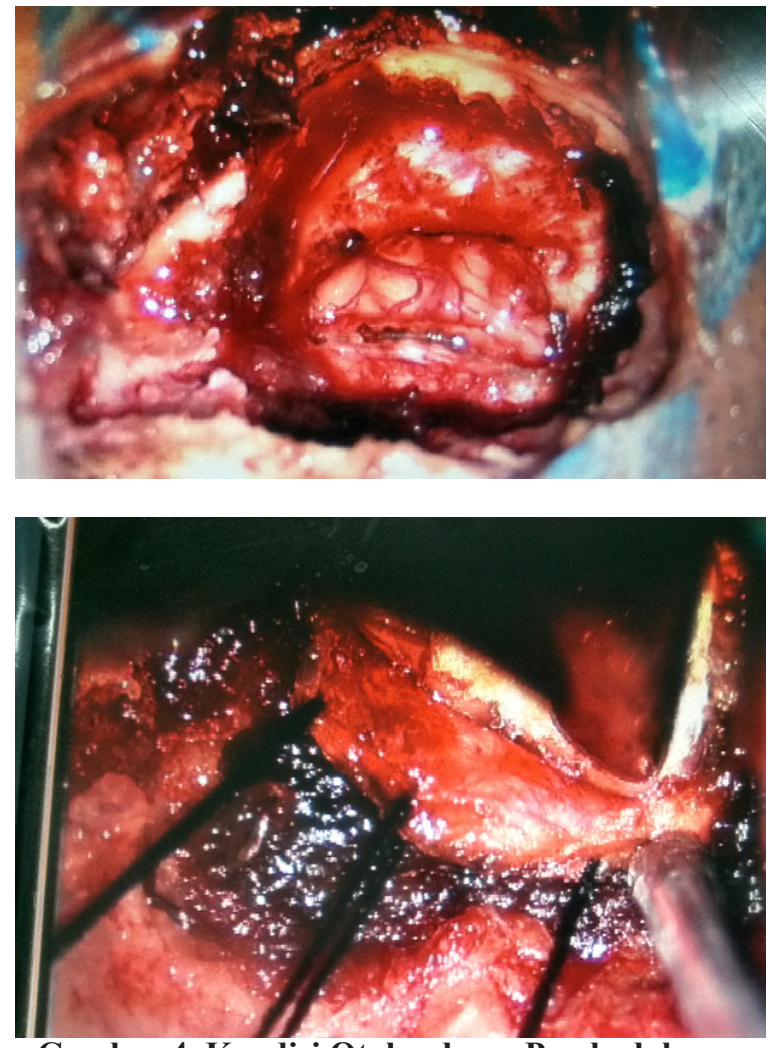

Gambar 4. Kondisi Otak selama Pembedahan

Tabel 2. Estimasi Cairan selama Pembedahan

\begin{tabular}{lll}
\hline Output & Input & Balance \\
\hline $\begin{array}{l}\text { Urine 2700 cc/9 } \\
\text { jam }\end{array}$ & Kristaloid 2500 cc & $\begin{array}{l}\text { Defisit 150 } \\
\text { cc } \\
\text { Perdarahan }\end{array}$ \\
$1100 \mathrm{cc}$ & Koloid $500 \mathrm{cc}$ & \\
& & \\
& Mannitol 200 cc & \\
& PRC 750 cc & \\
\hline
\end{tabular}

\section{Pengelolaan Pascabedah}

Pascapembedahan dilakukan delayed emergence. Pasien dibawa ke ICU (Intensive care unit) dalam keadaan terintubasi dan ventilasi terkontrol. Dilakukan CT Scan kontrol 6 jam pascapembedahan. Weaning bertahap dan ekstubasi dengan difasilitasi lidokain di ICU setelah evaluasi CT Scan dinilai aman pada besok harinya. Penilaian defisit neurologis pasca ekstubasi kembali pada kondisi preoperatif bahkan terjadi pengurangan terhadap keluhan nyeri kepala dan kelemahan ekstremitas. Setelah 2 hari perawatan ICU, pasien kembali ke ruangan.
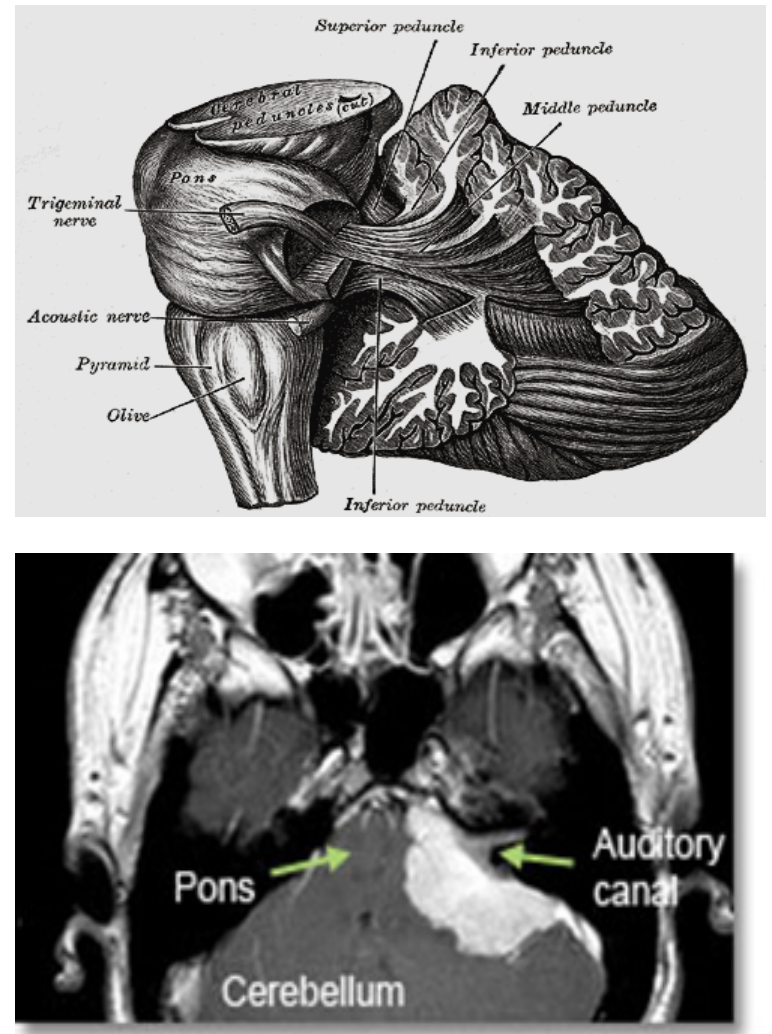

Gambar 5. Cerebellopontine Angle.

\section{Pembahasan}

Tumor Cerebello Pontine Angle (CPA) adalah tumor intrakranial yang berada pada sudut cerebellopontine. Cerebello Pontine Angle (CPA) merupakan ruang kecil di fossa posterior yang dibatasi oleh cerebellum dan pons, berbentuk irreguler dan berisi nervus VII, nervus VIII, flocculus cerebellum dan recess lateral ventrikel ke-4. Cerebello Pontine Angle (CPA) dibatas oleh permukaan posterior dari os temporal pada sisi anterior, permukaan anterior cerebellum pada sisi posterior, olive anterior pada sisi medial, tepi inferior pons dan pedunkulus cerebelli pada sisi superior dan tonsil cerebelli pada sisi inferior., ${ }^{3,4,7}$ Lokasi yang berhubungan dengan banyak struktur inilah yang menjadi khusus terhadap pembedahan tumor CPA. Pendesakan ataupun infiltrasi jaringan tumor pada struktur sekitar akan menimbulkan gejala defisit neurologis yang khas. Tumor CPA yang paling umum adalah vestibular schwannoma atau disebut juga neuroma akustik. Kurang lebih $8 \%$ dari tumor primer intrakranial 


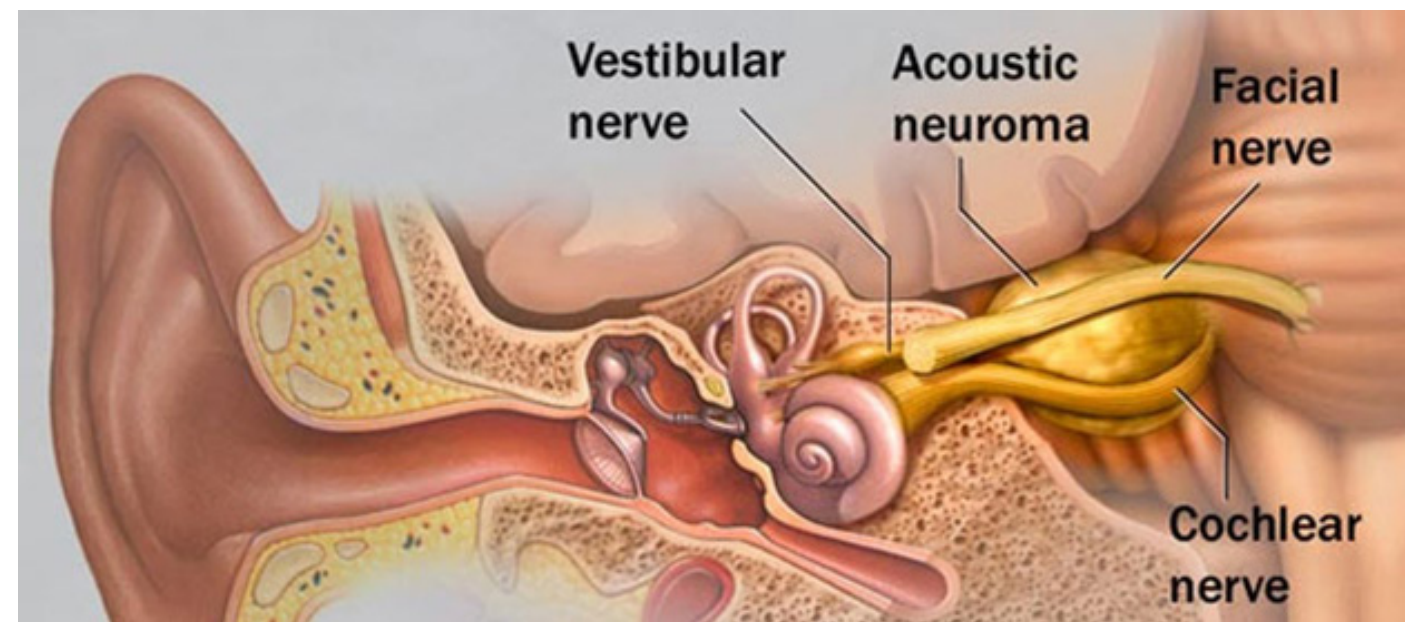

Gambar 6. Vestibular Schwannoma (Neuroma Akustik). ${ }^{11}$

adalah schwannoma, dengan lokasi terbanyak terdapat pada CPA, dimana $90 \%$ adalah vestibular schwannoma dan hanya $10 \%$ tipe lainnya. Perbandingan dengan vestibular schwannoma, tanda dan gejala dari nervus VIII adalah jarang, tanda dan gejala dari nervus cranialis lainnya dan tanda cerebellum lebih menonjol pada tumor CPA non vestibular schwannoma. Dengan bantuan computed tomography dan magnetic resonance imaging (MRI) sering menunjukkan gambaran yang mengarah ke diagnosis yang benar. ${ }^{8,9}$ Secara epidemiologi neuroma akustik (NA) banyak

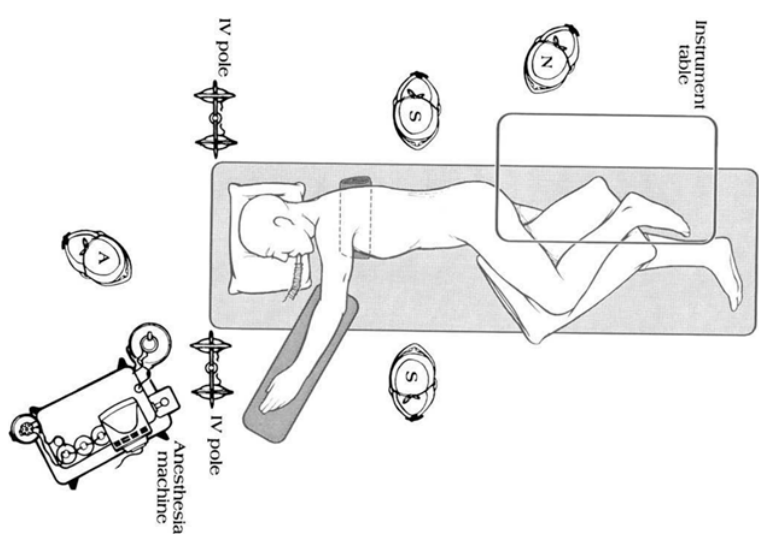

Gambar 7. Posisi Lateral. Posisi lengan $90^{\circ}$, peletakan bantalan diantara Tngkai dan chest roll positioning. ${ }^{12}$

akustik internus, stage II jika didapatkan tumor CPA dengan atau tanpa fraksi meatus akustik internus, stage III jika tumor CPA telah melekat pada batang otak dan stage IV jika tumor CPA disertai dengan penekanan batang otak dan invasi pada usia pertengahan. Pada pasien dengan neurofibromatosis dapat muncul lebih awal yaitu pada dekade ketiga. Pada suatu penelitian dari 500 kasus NA dilaporkan terdapat $50 \%$ pasien berusia pada dekade kelima atau keenam dan hanya $15 \%$ yang berusia kurang dari 30 tahun. Neuroma akustik sangat jarang terjadi pada anakanak. Neuroma akustik terhitung $60-92 \%$ dari tumor CPA. Oleh karena itu saat mengevaluasi massa CPA primer, NA adalah yang tersering. ${ }^{8,9}$ Neuroma akustik dapat dikelompokan menurut skala WT Koos. Stage I jika tumor di dalam meatus

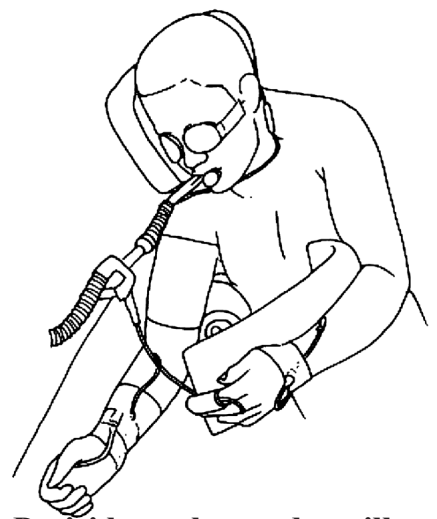

Gambar 8. Posisi bantalan pada axillar (axillary roll). Bantalan di posisikan disisi kaudal dari aksila. $^{12}$

arachnoid.3 Pada kasus ini menurut skala WT Koss maka dapat dikategorikan stage IV, dimana sudah ada penekanan pada batang otak berupa herniasi upward dan hydrocephalus. Gambaran klinis NA tergantung ukuran dan lokasi tumor. 
Gejala yang dapat terjadi antara lain: tinitus unilateral, kehilangan pendengaran sensorineural unilateral, vertigo, ketidakseimbangan, lemah separuh wajah, penurunan refleks kornea, hemihipestesi pada wajah atau nyeri pada sisi ipsilateral wajah. Dengan pertumbuhan tumor lebih lanjut, serebelum dan batang otak dapat terkompresi dan menyebabkan masalah yang berkaitan dengan keseimbangan dan koordinasi. Ataksia dan tremor intensional mungkin akan berkembang. Pasien akan memiliki kecenderungan untuk jatuh ke sisi lesi. Jika perkembangan tumor makin membesar dapat menyebabkan peningkatan tekanan intrakranial dan hidrosephalus sehingga pasien akan merasa sakit kepala berat. ${ }^{8,9}$ Kasus yang kami kerjakan mempunyai gejala khas peningkatan TIK dimana keluhan sakit kepala progresif disertai kelemahan pada salah satu sisi ekstremitas gerak. Untuk spesifik yang berhubungan dengan saraf kranialis adalah adanya gangguan pendengaran dan asimetris pada wajah.

Pemeriksaan untuk kecurigaan NA harus mencakup pemeriksaan pendengaran, nervus kranialis, fungsi okulomotor dan serebelum. Pemeriksaan telinga harus mencakup otoskopi. Hasil Otoskopi yang normal akan membantu menyingkirkan penyebab lain dari gangguan pendengaran. Tes garpu tala dapat membantu mengetahui sisi dengan gangguan sensorineural. Nervus kranialis harus diperiksa dengan perhatian khusus pada nervus III, VII, VIII, IX, X, XII, dan periksa tanda-tanda nystagmus. Pemeriksaan fungsi cerebellum mencakup tunjuk jari hidung untuk pengujian tremor intensi, tes Romberg, dan jalan tandem. Pasien dengan tumor CPA sering jatuh ke arah sisi lesi. ${ }^{9}$ Hasil pemeriksaan harus didokumentasikan dengan baik karena luaran pembedahan berhubungan dengan fungsi sarafsaraf kranialis tersebut. Penatalaksanaan anestesi pada tumor CPA sama dengan penatalaksanaan anestesi pada pembedahan tumor fossa posterior lainnya, karena CPA secara anatomi merupakan bagian dari fossa posterior, dimana pada CPA ini banyak terdapat saraf vital, pembuluh darah. Sehingga pada pembedahan tumor ini memerlukan perhatian khusus, halus, sulit dan waktu yang lama. Berkaitan dengan hal tersebut, maka pengelolaan anestesi harus dilakukan secara holistik dan teliti pada evaluasi prabedah atau preoperatif, persiapan dan premedikasi, pengawasan kondisi pasien secara umum, pemilihan posisi selama tindakan bedah, serta memfasilitasi pengawasan fungsi saraf cranial, stabilisasi pernafasan, kardovaskular, mencegah dan memonitor terjadinya emboli udara serta komplikasi lain yang dapat terjadi. ${ }^{1,6,7}$

Evaluasi preoperatif yang perlu diperhatikan adalah tanda-tanda peningkatan TIK meliputi tingkat kesadaran, muntah, edema papil, hidrosefalus, gangguan defisit saraf cranial seperti sulit menelan, gangguan fungsi laring, perubahan fonasi, gag reflek menghilang, tanda gangguan fungsi batang otak seperti nafas tidak teratur, sleep apneu, tanda gangguan cerebellar seperti ataxia, dysmetria dan gangguan kardiovaskular seperti bradikardi. ${ }^{7-9}$ Diagnosis dan pengelolaan dilakukan utamanya untuk mengetahui hubungan antara topografi lesi dan gangguan fungsi yang terjadi. Pada kasus ini hasil pemeriksaan preoperatif menunjukkan gangguan pendengaran, hemiparesis dextra, paresis N.VII dextra dan peningkatan TIK. Untuk saraf kranialis yang berhubungan dengan jalan nafas masih berfungsi dengan baik, tetapi tidak menutup kemungkinan komplikasi tindakan dapat menurunkan fungsi saraf kranialis tersebut.

Selama proses pembedahan, menentukan posisi yang adekuat pada pasien merupakan faktor yang penting dalam memberikan akses yang memadai untuk penanganan lesi intrakranial. Posisi pasien yang dapat diterapkan pada pembedahan fossa posterior adalah posisi lateral, posisi telungkup (prone), posisi semi telungkup (park-bench), posisi duduk (sitting) dan posisi terlentang (supine). Penentuan posisi tergantung dari metoda pembedahan yang akan dilakukan. ${ }^{10}$ Disamping posisi yang benar, beberapa hal penting perlu dilakukan sebagai pencegahan umum, yaitu memberikan perhatian khusus pada penggunaan bantalan, untuk menghindari peregangan atau kompresi dari saraf perifer dan pembuluh darah. Selain itu, pengamanan jalan nafas dalam perubahan posisi kepala juga perlu diperhatikan. Semua jalur arteri dan vena harus dibebaskan 
Tabel 3. Tindakan Pengawasan Berdasarkan Periode Tindakan Operatif. ${ }^{19}$

\begin{tabular}{|c|c|}
\hline Pra Induksi \& Induksi & Pasca Induksi \\
\hline EKG 5 leads & Kateter vena sentral \\
\hline Tekanan darah & $\begin{array}{l}\text { Pemeriksaan precordial } \\
\text { Doppler Ultrasound }\end{array}$ \\
\hline Pulse oxymetri & Stetoskop esophageal \\
\hline Steeoskop precordial & $\begin{array}{l}\text { Pemeriksaan temperatur } \\
\text { esophageal/nasofaringeal }\end{array}$ \\
\hline $\mathrm{ETCO}_{2}$ & $\mathrm{ETCO}_{2}$ dan $\mathrm{ETN}_{2}$ \\
\hline Elektrofisiologis* & Transesofageal* \\
\hline $\begin{array}{l}* \text { jenis pengawasan } \\
\text { yang tidak rutin dilaku- } \\
\text { kan }\end{array}$ & \\
\hline
\end{tabular}

dan jika dimungkinkan, dapat diakses dengan segera. Dan yang paling penting adalah antisipasi dan diagnosis dini serta persiapan penanganan terjadinya emboli udara. ${ }^{11}$

Posisi untuk dilakukan pembedahan pada CPA pada pasien ini adalah posisi lateral. Posisi lateral digunakan untuk pendekatan lesi yang tidak berada di garis tengah, terutama CPA. Posisi ini memfasilitasi retraksi karena gravitasi dari otak kecil yang bebas sehingga memfasilitasi aliran CSS dan darah vena. Posisi lateral sangat cocok untuk dapat melakukan pendekatan pada daerah CPA. Selain itu, dengan posisi ini operator bedah dapat mengakses daerah-daerah yang mengalami lesi seperti cerebellar hemisphere, clivus, petrous ridge, serta foramen magnum. Namun, kebanyakan posisi ini digunakan untuk prosedur bedah saraf unilateral pada bagian fossa posterior. Kerugian posisi ini adalah kemungkinan terjadi kelumpuhan saraf popliteal akibat bantalan yang kurang adekuat pada daerah fibula. Selain itu penggunaan axillary roll harus tepat agar dapat melindungi struktur saraf dan vaskuler pada bagian axillar. Axillary roll sebaiknya tidak diletakkan terlalu dalam pada axillar karena posisi yang tepat dapat sedikit mengangkat toraks dan dekompresi pada ipsilateral aksila. Pada posisi lateral, lengan seringkali diposisikan pada double armboard, papan atau bantalan yang terbuat dari logam yang dikaitkan pada meja pembedahan setelah memposisikan pasien. Kelumpuhan saraf radialis bisa terjadi karena penempatan posisi pasien yang kurang tepat dan terjadi penekanan nervus radialis yang terus menerus akibat tekanan bagian tepi armboard. ${ }^{11,12}$

Pemberian premedikasi dipertimbangkan, tergantung pada status fisik pasien. adanya peningkatan TIK dan tingkat kegelisahan pada pasien. Pemberian sedatif perlu dihindari, jika memang diperlukan dapat digunakan dengan dosis minimum. Pengaruh lesi pada kardiovaskular dan respirasi menjadi nyata setelah pemberian premedikasi yang bersifat sedatif dan mendepresi pernafasan. Sehingga secara umum premedikasi tidak diberikan pada lesi fossa posterior. Kecuali memang premedikasidibutuhkan. ${ }^{13,14}$ Premedikasi dengan golongan narkotika dihindari pada pasien dengan hidrosefalus akibat pembuntuan ventrikel ke-IV, karena dapat meningkatkan TIK. Benzodiazepin per oral dapat diberikan 60-90 menit sebelum pasien masuk ruang pembedahan untuk mengurangi kegelisahan dan tidak berefek samping pada pingkatan TIK. ${ }^{15}$ Pada pasien ini diberikan ondansentron $8 \mathrm{mg}$ dan ranitidine $50 \mathrm{mg}$ diruangan. Sedangkan midazolam 2.5 mg di kamar pembedahan, dimana midazolam menyebabkan penurunan aliran darah otak dan $\mathrm{CMRO}_{2}$ secara paralel. Midazolam dibandingkan thiopental memberikan hemodinamik lebih stabil. Pada pasien tumor otak terjadi penurunan sedikit dari MAP dan tekanan perfusi otak cenderung tidak turun. Benzodiazepin adalah hipnotik sedatif yang mempunyai rentang lebih besar, berefek anxyiolisis, anti konvulsan, dan amnesia. Benzodiazepin menyebabkan depresi SSP sesuai dengan dosis sehingga terjadi penurunan $\mathrm{CMRO}_{2}$, aliran darah otak, dan mempunyai efek proteksi otak walaupun kurang jika dibandingkan dengan barbiturat. Midazolam memiliki potensi 3-4 kali diazepam dengan mula kerja dan pemulihan yang lebih cepat. Tekanan darah turun bila ada hipovolemia akibat turunnta resistensi peirfer dan curah jantung, penurunan aliran darah otak dan $\mathrm{CMRO}_{2}$ sebanyak $40 \%{ }^{15}$

Jalan nafas pada pasien perlu mendapat perhatian khusus, terutama berkaitan dengan posisi pasien selama pembedahan. Ahli anestesi harus dapat melakukan fiksasi pipa endotrakheal sebelum 
penentuan posisi bedah pada pasien, terutama pada posisi bedah yang melibatkan posisi kepala dan leher yang mungkin mengalami rotasi. ${ }^{15}$ pengawasan tekanan darah harus dilakukan sebelum induksi anestesi sehingga saat dilakukan induksi dan intubasi kontrol terhadap tekanan darah dan CPP dapat maksimal, khususnya pada pasien dengan risiko peningkatan TIK. Tehnik indukasi anestesi dengan thiopental atau propofol intravena dilanjutkan dengan menggunakan golongan narkotika dosis rendah (Fentanyl 4-6 $\mu \mathrm{g} / \mathrm{kg}$ ), relaksan otot dan anestesi inhalasi sebesar 0,5-1,0 MAC dapat menghasilkan efek anesthesia dan amnesia yang adekuat, pemeliharaan aktivitas sistim saraf autonom dan pasien akan segera sadar setelah anestesi inhalasi dihentikan. Dengan demikian, penilaian status neurologis pascapembedahan dapat segera dilakukan. ${ }^{10,15}$ Lidokain berdasarkan literatur digunakan sebagai adjuvant brain protection. Pemberian lidokain menurunkan $\mathrm{CMRO}_{2}$ 15-20\%. Dosis yang direkomendasikan $1.5 \mathrm{mg} / \mathrm{kgbb}$. Tujuan lain penggunaan lidokain untuk menurunkan respon hemodinamik sewaktu dilakukan tindakan intubasi. ${ }^{17}$ Pada kasus ini digunakan lidokain $80 \mathrm{mg}$ intravena saat induksi dengan harapan tidak terjadi gejolak hemodinamik yang dapat meningkatkan tekanan darah rerata dan lidokain mempunyai efek proteksi otak. Mekanisme lidokain dalam proteksi otak adalah menurunkan perpindahan ion transmembran, menurunkan laju metabolisme otak (cerebral metabolitrate-CMR), modulator aktifitas leukosit dan menurunkan pelepasan excitotoxin karena iskemia. ${ }^{19}$

Relaksasi pada pasien ini menggunakan pelumpuh otot rocuronium dan vecuronium. Relaksasi digunakan untuk mencapai TOF (Train of Four) 0 , karena jika TOF 1 tidak menjamin tidak adanya gerakan diafragma yang akan meningkatkan tekanan vena serebral dan tekanan intracranial. Apneu dengan narkotik atau hiperventilasi tidak dianjurkan karena akan menyebabkan kenaikan tekanan vena serebral. Vecuronium dipilih pada kasus ini karena tidak menyebabkan pelepasan histamin yang dapat gejolak hemodinamik dan tidak meningkatkan aliran darah ke otak yang dapat menyebabkan edema. Vecuronium juga mempunyai efek minimal atau tidak ada efeknya pada ICP, tekanan darah, denyut jantung dan efektif pada pasien dengan SOL ataupun iskemia. Rocuronium merupakan alternatif terbaik karena onset cepat dan sedikit pengaruhnya pada dinamika intrakranial. ${ }^{18}$

Pemeliharaan anestesi harus mempunyai efek paling kecil atau tidak mempengaruhi autoregulasi serebral dan kemampuan merespon $\mathrm{CO}_{2}$, mempertahankan kestabilan kardiovaskular, dan mampu menurunkan TIK sehingga meningkatkan tekanan perfusi otak. Anestesi inhalasi yang paling ideal dikatakan adalah sevofluran. Pada pasien ini digunakan inhalasi isofluran karena pertimbangan biaya untuk operasi yang lama. Isofluran merupakan obat anestesi inhalasi yang baik untuk neuroanestesi yang menurunkan $\mathrm{CMRO}_{2} 50 \%$ pada $2 \mathrm{MAC}$, akibat penurunan fungsi neuron bukan toksisitas metabolik, dosis isofluran yang lebih tinggi tidak menimbulkan perubahan seperti pentotal. Pada konsentrasi $0,5 \%$ isofluran menurunkan aliran darah otak, sedangkan $0,95 \%$ meningkatkan aliran darah otak. Autoregulasi terganggu oleh isofluran tetapi tetap berfungsi samai 1,5 MAC. Respons terhadap hipokapnia masih baik sampai 2,8 MAC, tetapi pada dosis ini kenaikan $\mathrm{PaCO}_{2}$ gagal untuk mempengaruhi aliran darah otak, karena pemuluh darah otak berdilatasi maksimal. Dengan isofluran aliran darah otak meningkat, tetapi ada penurunan resistensi absorpsi cairan serebrospinal. ${ }^{16,17}$

Anestesi inhalasi pada pasien ini dikombinasi dengan propofol kontinyu. Selain mengambil efek proteksi otak dari propofol, tujuan kombinasi adalah menurunkan dosis obat inhalasi yang dipakai. Propofol terhadap tekanan perfusi otak dengan menurunkan tekanan darah. Efek propofol terhadap metabolism otak dan aliran darah otak sama dengan barbiturate. Pada pasien dengan cidera otak anestesi dengan propofol akan menurunkan aliran darah otak sebanyak $30 \%, \mathrm{CMRO}_{2} 30 \%$, dan tekanan intracranial, dan penurunan tekanan perfusi otak disebabkan karena penurunan tekanan darah. Propofol mendepresi jantung lebih kuat dari thiopental, tekanan darah turun 15-30 \% yang disertai atau tidak reflex peningkatan denyut nadi. Sehingga sebelum induksidipastikan kecukupan 
volume pasien. Propofol lebih efektif mencegah respon hemodinamik di banding etomidat dan thiopental. ${ }^{18,19}$

Pemberian kortikosteroid pada kasus tumor otak untuk mengurangi edema disekeliling tumor. Pemberian steroid sebelum reseksi tumor sering memberikan perbaikan neurologis mendahului pengurangan tekanan intrakranial. Steroid dapat memperbaiki kerusakan barier darah-otak. Pada kasus ini, steroid sudah diberikan sejak sebelum pembedahan. Banyak literatur menuliskan pemberian steroid menurunkan edema vasogenic peritumoral. Efek steroid melalui mekanisme stabilisasi membran, mencegah pelepasan lipid peroxidase dan anti inflamasi sehingga dapat sebagai proteksi kondisi iskemia otak. Selain steroid diberikan juga mannitol dengan dosis $0,5-1 \mathrm{gr} / \mathrm{kgbb}$ dengan tujuan menurunkan tekanan intrakranial (TIK), meningkatkan CPP dan memperbaiki aliran darah otak terutama pada daerah iskemia. ${ }^{18}$ Suhu tubuh dijaga pada rentang $35-36^{\circ} \mathrm{C}$ dengan tujuan mempertahankan kondisi low normothermia. Terdapat bukti-bukti dari kondisi tersebut sebagai upaya proteksi otak. Keuntungan low normothermia terbatas pada mencegah kejadian hipertermia yang sangat tidak menguntungkan dan menghindari efek samping dari kondisi hipothermia. Literatur menyarankan suhu tubuh di kamar operasi $34-35^{\circ} \mathrm{C}$ dan pascabedah di ICU $36{ }^{\circ} \mathrm{C} .{ }^{20}$

Tujuan terapi cairan untuk membuat hemodinamik stabil, mencegah hipovolemia, hipervolemia, hipoosmoler, hiperglikemia. Pemberian cairan dapat dengan $\mathrm{NaCl} \quad 0,9 \%$ atau dapat diberikan koloid, batasi pemberian Ringer laktat, dikarenakan $\mathrm{NaCl} \quad 0,95 \quad$ (308 $\mathrm{mOsm} / \mathrm{lt})$ dibanding dengan RL (273 mOsm/lt) osmolaritasnya mendekati osmolaritas tubuh (290 $\mathrm{mOsm} / \mathrm{tt}$ ). Cairan pemeliharaan diberikan 1-1,5 $\mathrm{ml} / \mathrm{kgBB} / \mathrm{jam}$ atau mengganti $2 / 3$ dari diuresis. Hindari pemakaian larutan hipotonik. ${ }^{15,16}$ Selama operasi total perdarahan cukup banyak, tetapi dengan resusitasi yang baik maka dapat tercapai kondisi yang stabil tidak hipovolemia. Tindakan pemantauan atau pengawasan pada periode pembedahan bertujuan untuk memastikan perfusi dari sistim saraf pusat terjadi dengan adekuat.
Selain itu juga untuk mempertahankan stabilitas sistim kardiorespirasi dan mendeteksi terjadinya emboli udara. ${ }^{14}$

Alat-alat pengawasan yang digunakan meliputi invasive monitoring (arterial blood pressure dan central vein pressure), EKG, pulse oxymetri, kapnograph, temperatur, kateter urin, dan pemeriksaan analisa gas darah durante. Tujuan anestesi pada kasus ini memfasilitasi brain relaksasi dan penurunan TIK, pemberian $\mathrm{N}_{2} \mathrm{O}$ terdapat kontroversi terutama dalam mencegah VAE maka perlu dihindari. Pengawasan durante yang perlu diperhatikan adalah stimulasi dari batang otak dan emboli udara. Stimulasi batang otak dan saraf kranial dapat menyebabkan hipotensi berat, bradikardi, takikardi, aritmia dan hipertensi. Hipertensi dapat terjadi akibat stimulasi dari saraf $\mathrm{V}$, area abu-abu periventrikel, formasi retikularis, atau nukleus traktus solitarius. Bradikardi dan nodal escape terjadi akibat stimulasi nervus vagus, sedangkan hipotensi akibat penekanan pada pons dan medulla. Stimulasi pada batang otak dapat menghasilkan gangguan aritmia ventrikular dan supraventikular yang dapat mengancam nyawa, sehingga pengawasan EKG harus bagus dan tidak terganggu oleh tindakan kauter. ${ }^{14-16}$

Hal yang harus dimonitor intrapembedahan adalah reflex kardiovaskuler, yaitu stimulasi dilantai ventrikel IV menimbulkan reflek medulla atau reflek trigeminal yang menyebabkan hipotensi dan bradikardi. Selain itu, pengawasan batang otak harus dilakukan, mengingat tindakan pembedahan pada CPA berisiko menyebabkan cedera saraf kranial. Untuk tindakan anestesi, pengawasan evoked electromyogram (EMG) dan somatosensory evoked potentials (SSEPs) sangat penting karena dapat dipengaruhi oleh pemberian relaksan otot, $\mathrm{N}_{2} \mathrm{O}$ serta obat anestesi inhalasi. ${ }^{14,15,18}$ Tindakan yang dilakukan ketika pascapembedahan tumor CPA bertujuan untuk mencegah hipoksemia atau ancaman gangguan nafas yang lain, deteksi terjadinya iskemic otot jantung, yaitu dengan pemberian oksigen, EKG dan Foto Thorax, pemeriksaan analisa gas darah secara berkala, serta jika dicurigai emboli arteri maka dilakukan kompresi hiperbarik. ${ }^{13,14}$ 
Beberapa hal penting yang harus diperhatikan pada pascapembedahan adalah pasien harus dapat sadar dengan segera, agar penilaian fungsi neurologis dapat segera dilakukan. Sedangkan untuk perencanaan ekstubasi di pertimbangkan dengan hati-hati untuk meminimalisasi batuk dan mengejan untuk menghindari terjadinya sakit tenggorokan, hipertensi, takikardia dan peningkatan TIK hingga dapat terjadi perdarahan. ${ }^{10}$ Pada kasus ini dilakukan delayed emergence dengan beberapa pertimbangan yaitu operasi lebih 7 jam, jumlah perdarahan banyak, masih ada sisa tumor, dan antisipasi gangguan saraf kranial yang berhubungan dengan jalan nafas, sehingga diperlukan pengawasan dan rewarming diruang ICU. CT-scan kontrol dilakukan 6 jam pascapembedahan karena antisipasi perdarahan oleh sisa tumor. Setelah dinilai aman maka dilakukan weaning bertahap dan ekstubasi difasilitasi lidokain.

Komplikasi yang dapat terjadi pasca tindakan bedah fossa posterior adalah aritmia, permasalahan jalan nafas, komplikasi neurologis serta terjadinya pneumocephalus dan emboli udara. Aritmia sering terjadi sebagai akibat tindakan manipulasi daerah batang otak, dekat pons dan serabut saraf V, IX dan X. Permasalahan jalan nafas berupa makroglosia dan pembengkakan jalan nafas atas dapat terjadi karena lamanya tindakan pembedahan sehingga terjadi pembuntuan vena serta drainase limfa. Komplikasi neurologis dapat terjadi akibat peregangan leher yang ekstrem sehingga terjadi midcervical quadriplegia. Tindakan dibedah di dekat serabut saraf VII-X dapat menyebabkan hilangnya reflex jalan nafas, disfagia dan disfonia. Kerusakan saraf perifer terutama brachial plexus, saraf ulnar dan peroneal dapat disebabkan oleh kesalahan posisi pasien. Pneumocephalus terjadi akibat kebocoran cairan serebrospinal sehingga terbentu ruangan terisi udara antara dura dan arachnoid. Hal ini menyebabkan ukuran otak menjadi berkurang. Pemberian $\mathrm{N}_{2} \mathrm{O}$ akan memperburuk kondisi, sehingga sebaiknya dihentikan 15 menit sebelum pembedahan selesai dan membiarkan $\mathrm{PaCO}_{2}$ meningkat. Emboli udara pada vena banyak terjadi pada pembedahan fossa posterior dengan posisi pasien duduk dan merupakan komplikasi yang paling sering terjadi (sekitar 50\%). Semakin tinggi posisi kepala terhadap jantung, semakin besar tingkat kejadian emboli udara. Tingkat mortalitas dan morbiditas berkaitan dengan jumlah dan tingkat udara yang masuk. ${ }^{14-6}$ Terdapat beberapa tindakan pengawasan terjadinya emboli udara vena selama periode pembedahan, yaitu Doppler ultrasound tranducer, kateter arteri paru-paru, ETCO $2, \mathrm{ETN}_{2}$, serta transesophageal echocardiography (TEE). Pada kasus ini dipasang stestokop prekordial dan pemantauan ET $\mathrm{CO}_{2}$. Apabila emboli udara ini terdeteksi maka harus segera dikoreksi, yaitu antara lain dengan menyiram area bedah dengan larutan saline dan menutup luka secepatnya, menghentikan penggunaan $\mathrm{N}_{2} \mathrm{O}$, memberikan terapi $\mathrm{O}_{2} \quad 100 \%$ dan infus intravascular serta pemberian vasopressor untuk hipotensi. ${ }^{10,14,20}$

\section{Simpulan}

Cerebellopontine Angle (CPA) adalah ruang kecil berbentuk ireguler yang terletak di fossa posterior. Untuk lesi yang tumbuh di dalam $\mathrm{CPA}$, diferensial diagnosa terdiri dari tiga tumor utama: neuroma akustik, meningioma, dan epidermoid. Penatalaksanaan pembedahan untuk tumor CPA dapat dilakukan dengan beberapa tehnik pembedahan yang membutuhkan posisi pembedahan dan posisi pasien yang khusus dan membutuhkan perhatian tersendiri. Persiapan pada pasien dengan lesi fossa posterior adalah evaluasi pra bedah, premedikasi, induksi, posisi durante, pengelolaan anestesi dan pengawasan. Pemberian premedikasi tergantung dari keadaan pasien. Posisi pembedahan fossa posterior true lateral mempunyai perhatian khusus yang wajib diawasi sepanjang waktu operasi oleh seorang ahli anestesi. Tatalaksana durante penting diperhatikan untuk stimulasi batang otak dan adanya komplikasi yang mungkin terjadi. Manajemen pascapembedahan diperhatikan untuk mencegah hipoksemia atau ancaman gangguan nafas yang lain, deteksi terjadinya iskemik otot jantung. Jika dilakukan ekstubasi maka pasien dihindarkan dari batuk dan mengejan. Prinsip proteksi otak pada pembedahan tumor adalah tercapainya relaksasi dari otak dan penurunan dari TIK. 


\section{Daftar Pustaka}

1. American Brain Tumor Association. Brain tumor statistics. Chicago: 2012. Diakses dari http://www.abta.org/about-us/news/braintumor-statistics

2. McCarthy BJ, Surawicz T, Bruner J, Kruchko C. Consensus conference on brain tumor. Neuro-Oncology 2002: 134-45.

3. Swieszewska I, Szurowska E, Kloc W, Dubaniewicz WM, Skorek A, Drozynska E, Stempniewcz M. Cerebellopontine angle tumours: radiologic-pathologic correlation and diagnostic difficulties. Folia Neuropathol 2006; 44: 274-81.

4. Hain TC. Acoustic Neuroma. 2014. Diakses dari http://www.dizziness-and-balance.com/ disorders/tumors/acoustic_neuroma.htm

5. Khaled A, Ahsan S, Joarder MA, Karim B, Chandy MJ, Nasir TA. Chondroma of the cerebellopontine angle: a case report. Pulse 2015; 8: 81-4.

6. Holanda A. Schwannoma and meningioma association of cerebellopontine angle. Neurocirurgica de Chile 2013; 39: 170-71.

7. Springborg JB, Poulsgaard L, Thomsen J. Nonvestibular schwannoma tumors in the cerebellopontine angle: a structured approach and management guidelines. Skull Base 2008; 18: 217-27.

8. Gonzales MF. Classification and pathogenesis of brain tumors. Churchill Livingstone: New York; 1995, 31-45.

9. Berger MS, Prado MD. Textbook of NeuroOncology. Elsevier Saunders: Pennsylvania; 2005.

10. Harijono B, Saleh CS. Tata kelola anestesi pada bedah fossa posterior. Jurnal
Neuroanestesia Indonesia 2012; 1(4):311-19.

11. Patel SJ, Wen DY, Haines SJ. Posterior fossa: surgical consideration. Dalam: Cottrell JE, Smith DS, eds. Anesthesia and Neurosurgery, 4th Ed, Missouri; Mosby, Inc: 2001, 319-33.

12. Schubert A. Positioning injuries in anesthesia: an update. Advances in Anesthesia 2008; 26: $31-65$.

13. Saleh CS. Sinopsis Neuroanestesia Klinik. Surabaya: Universitas Airlangga Pers; 201.

14. Gheorghita E, Ciurea J. Considerations on anesthesia for posterior fossa-surgery, Romanian Neurosurgery, Emergency Hospital Bagdasar Arseni, Bucharest; 2012, XIX 3: 183-92.

15. Smith DS. Anesthetic management for posterior fossa surgery: Dalam Cotrell JE, Young WL, eds. Cottrel and Young's Neuroanesthesia, 5th Ed, Philadelphia: Mosby, Inc; 2010, 203-7.

16. Goldsack C. Posterior fossa surgery: Dalam Gupta AK, Summors A, eds. Notes in Neuroanesthesia and Critical Care, edisi-1. London: Greenwich Medical Media. Ltd; 2001, 57-60.

17. Lalenoh D, Bisri T, Yusuf I. Brain protection effect of lidocaine measured by interleukin- 6 and phospholipase A2 concentration in epiduralhaematomawithmoderateheadinjury patient. J Anesth Clin Res 2014; 5(3): 1-3.

18. Menon G, Nair S, Bhattacharya RN. Cerebral protection - Current concepts. IJNT 2005; 2(2): 67-9.

19. William FC. Management of suprasellar meningioma. J Neuro-Ophthalmology 2003; 23(1): $1-2$.

20. Bisri T. Dasar-Dasar Neuroanestesi, edisi ke2. Bandung: Saga Olah Citra; 2008, 1-74. 